\title{
EFFECTS OF WATER CONTENT DISTRIBUTION ON HYDRAULIC CONDUCTIVITY OF PREHYDRATED GCLS AGAINST CALCIUM CHLORIDE SOLUTIONS
}

\author{
TAKeshi Katsumi ${ }^{i)}$, Hiroyuki Ishimori ${ }^{\text {ii) }}$, Atsushi Ogawa ${ }^{\text {iii) }}$, \\ Satoshi Maruyama ${ }^{\text {iii) }}$ and Ryoichi FukagawA ${ }^{\text {iv) }}$
}

\begin{abstract}
When geosynthetic clay liners (GCLs) are applied as bottom liners at waste containment facilities, they are naturally prehydrated by absorbing moisture in the underlying base layers. In order to evaluate the effects of cations contained in waste leachates, this study investigated the effects of the water content distribution of the GCLs prehydrated with actual soils on their hydraulic conductivities against $\mathrm{CaCl}_{2}$ solutions. The "prehydration tests", which were conducted prior to the hydraulic conductivity tests, showed that the water content distribution of the prehydrated GCLs depends on the properties of the GCLs and the base layers. In particular, drastic differences between GCLs with powdered bentonite and GCLs with granular bentonite were observed in the prehydration water content and its distribution. Prehydrated GCLs with powdered bentonite had a higher water content and a more homogenous distribution than those with granular bentonite. The hydraulic conductivity tests showed that most of the prehydrated GCLs exhibit a low hydraulic conductivity of $k \approx 1.0 \times 10^{-8} \mathrm{~cm} / \mathrm{s}$ against $\mathrm{CaCl}_{2}$ solutions with $0.1-0.5 \mathrm{M}$. However, GCLs with granular bentonite may be difficult to homogeneously prehydrate and exhibit an unstable hydraulic conductivity, which varies from $k=2.9 \times 10^{-9} \mathrm{~cm} / \mathrm{s}$ to $k=1.5 \times 10^{-6} \mathrm{~cm} / \mathrm{s}$. The homogeneity of the water content distribution has been considered an important factor to obtain a required barrier performance under prehydration conditions, which are naturally generated in actual sites.
\end{abstract}

Key words: chemical resistance, geosynthetic clay liner, hydraulic conductivity, prehydration (IGC: D4)

\section{INTRODUCTION}

Geosynthetic clay liners (GCLs) are manufactured clay liners, which consist of a thin layer of bentonite glued to a geomembrane or encased by geotextiles. Due to their relatively low cost, easy installation, long-term stability, deformability, and excellent barrier performance to water, GCLs are effective barrier materials that can be used as alternatives or combined with previous barrier materials. Thus, GCLs have been used all over the world for various applications such as to seal ponds, lagoons, and landfills.

GCLs are increasingly being used as a component of present bottom liner systems in waste containment facilities. However, basic performance and fundamental factors in addition to estimating the performance in the peculiar conditions of a waste containment facility must be considered when designing a bottom liner system. Many researchers have studied the performance of GCLs in a laboratory setting; for example, the hydraulic and mechanical behavior involved in overlapping and partial deformation (Barroso et al., 2006; Daniel et al., 1997; Dickinson and Brachman, 2006; Giroud et al., 2002; LaGatta et al., 1997; Rowe and Orsini, 2003; Touze-Foltz et al., 2006; Viswanadham et al., 1999), the transport properties of chemical solutions (Lake and Rowe, 2000, 2004), the hydraulic conductivity against chemical solutions and long-term stability (Jo et al., 2001; Katsumi et al., 2005, 2007; Kolstad et al., 2004a; Petrov and Rowe, 1997; Ruhl and Daniel, 1997; Shackelford et al., 2000; Shan and Lai, 2002), and so on. Although most of these reports focus on the performance evaluation of the GCLs themselves, few reports investigate the effects of geological and hydrological conditions in actual sites on the performance of the GCLs.

Prehydration is one factor that affects the barrier performance of GCLs in actual sites. Prehydration hydrates the bentonites in the GCLs before exposing to chemical solutions such as waste leachates. Because chemical solutions seriously deteriorate the swelling capacity and barri-

i) Associate Professor, Graduate School of Global Environmental Studies, Kyoto University, Japan (tkatsumi@mbox.kudpc.kyoto-u.ac.jp).

i) Department of Civil Engineering, Ritsumeikan University, Japan.

iii) Formerly Graduate Student, ditto.

iv) Professor, ditto.

The manuscript for this paper was received for review on June 29, 2007; approved on April 8, 2008.

Written discussions on this paper should be submitted before January 1, 2009 to the Japanese Geotechnical Society, 4-38-2, Sengoku, Bunkyo-ku, Tokyo 112-0011, Japan. Upon request the closing date may be extended one month. 
er performance of bentonites (Laird, 2006; Norrish, 1954; Norrish and Quirk, 1954; Posner and Quirk, 1964; Rowe, 1998, 2005; Rowe et al., 2004; Slade and Quirk, 1990; Slade et al., 1991), prehydration has been considered an effective measure for improving barrier performance and chemical resistance of bentonites (Daniel et al., 1993; Lee and Shackelford, 2005; Shackelford, 1994; Vasko et al., 2001). When GCLs are applied to bottom liners at waste containment facilities, the GCLs are naturally prehydrated because the bentonites in the GCLs absorb moisture in the underlying base layer on which the GCLs are installed.

It is important to clarify the prehydration effects on the hydraulic conductivity of the entire prehydrated GCL in order to improve the design of bottom liner systems in waste containment facilities. However, limited data on the barrier performance of GCLs naturally prehydrated on an unsaturated base layer soil has been reported. This study aims to investigate (1) the heterogeneity of the water content distribution of prehydrated GCLs, (2) the hydraulic conductivity of the prehydrated GCLs against $\mathrm{CaCl}_{2}$ chemical solutions, and (3) the relationship between the water content distribution and the hydraulic conductivity of the prehydrated GCLs.

\section{BACKGROUND}

When GCLs are used as hydraulic barrier materials to contain chemical substances, barrier performance deterioration must be closely monitored. The barrier performance of GCLs directly exposed to leachates at waste containment facilities deteriorates because the bentonite in GCLs has insufficient swelling against electrolytic chemical solutions. It has been reported that the hydraulic conductivity value increases as the concentration and/or ionic valence of the electrolytic solution increases (Jo et al., 2001; Katsumi et al., 2007; Kolstad et al., 2004a; Shan and Lai, 2002). Because deterioration is due to such chemical attacks, many researchers have developed and proposed methods to improve the chemical resistance of GCLs. Some methods include (1) to use chemical resistance bentonites (Katsumi et al., 2006, 2008; Kolstad et al., 2004b, 2006; Lo et al., 1994, 1997; Onikata et al., 1996, 1999a, 1999b; Trauger and Darlington, 2000; Lo and Yang, 2001; Gates, 2004; Gates et al., 2004; Yang and Lo, 2004), (2) to hydrate bentonites before exposing to chemical solutions (Daniel et al., 1993; Lee and Shackelford, 2005; Shackelford, 1994; Vasko et al., 2001), and (3) to confine bentonites with a higher effective pressure (Katsumi et al., 2005; Petrov and Rowe, 1997).

Hydrating bentonites before exposing to chemical solutions is called "prehydration". Bentonites prehydrated with pure water have been considered to have a lower hydraulic conductivity to chemical solutions than nonprehydrated bentonites (Daniel et al., 1993; Lee and Shackelford, 2005; Vasko et al., 2001). These reports represent the necessary water contents to satisfy the required barrier performance. For example, Bonaparte et al. (1996) have considered that the prehydration water content of GCLs exhibits $40-100 \%$ in actual sites, but they did not show the hydraulic conductivity values of the prehydrated GCLs. Moreover, Vasko et al. (2001) have investigated the water content and its distribution of the prehydrated GCLs, and then evaluated the hydraulic conductivity values. However, their GCL prehydration method differs from the actual process that GCLs absorb moisture from the unsaturated base layers; they used filter papers instead of the base layers. Hence, it should be clarified how prehydration effects induced in actual sites influence the water content distribution, its homogeneity, and the hydraulic conductivity of GCLs. Although Lee and Shackelford (2005) showed the hydraulic conductivity of prehydrated GCLs against chemical solutions, the prehydrated GCLs were prepared by permeating the fresh water into them in the apparatus for the hydraulic conductivity tests before permeating the chemical solutions.

These reports are not applicable when bentonite materials are heterogeneously prehydrated. Even if the sufficiently swelled parts included in the heterogeneously prehydrated bentonite material can exhibit the low hydraulic conductivity, the insufficiently swelled parts exhibit the high hydraulic conductivity so that the hydraulic conductivity of the entire bentonite material with the heterogeneous water content distribution becomes high. In the base layer at real sites, GCLs are rarely prehydrated without heterogeneity of the water content distribution. Thus, it is necessary to investigate the barrier performance of GCLs prehydrated on a base layer soil considering the real prehydration process.

\section{EXPERIMENTAL METHODS}

To investigate the prehydration effects on barrier performance of GCLs, a prehydration test was initially conducted to prepare the prehydrated GCLs before the hydraulic conductivity test. Forty-nine GCL specimens were prehydrated under the various testing conditions. Among the 49 GCL specimens, 25 specimens were used for the hydraulic conductivity test to evaluate the hydraulic conductivity, while others were used to evaluate the water content distribution (in particular, the average and the heterogeneity of its distribution) of the GCLs. Finally, the prehydration effects on the barrier performance of GCLs were discussed by relating the water content distribution of a GCL to its hydraulic conductivity. Detailed experimental conditions and methods are described below.

\section{Materials Used}

Two types of GCLs where sodium bentonite was encapsulated between a polypropylene woven geotextile and a polypropylene nonwoven geotextile by needlepunching fibers were used. One had powdered bentonite (Bentofix NPS 4900-1), while the other had granular bentonite (Bentofix NPS 4900-2). The mass per unit area of each GCL was $4.73 \mathrm{~kg} / \mathrm{m}^{2}$ (the data provided by the manufac- 
Table 1. Properties of bentonites in GCLs used

\begin{tabular}{|c|c|c|c|c|}
\hline Property & Unit & Standard & $\begin{array}{c}\text { Powdered } \\
\text { bentonite GCL }\end{array}$ & $\begin{array}{c}\text { Granular } \\
\text { bentonite GCL }\end{array}$ \\
\hline Soil particle density & {$\left[\mathrm{g} / \mathrm{cm}^{3}\right]$} & JIS A 1202 & 2.839 & 2.803 \\
\hline Natural water content & {$[\%]$} & JIS A 1203 & 10.02 & 8.50 \\
\hline Plastic limit & [\%] & JIS A 1205 & 51.0 & 52.2 \\
\hline Liquid limit & [\%] & JIS A 1205 & 619.5 & 630.0 \\
\hline Hydraulic conductivity & {$[\mathrm{cm} / \mathrm{s}]$} & ASTM D 5084 & $2.24 \times 10^{-9}$ & $6.71 \times 10^{-9}$ \\
\hline Swell index & {$[\mathrm{mL} / 2 \mathrm{~g}$-solid] } & ASTM D 5890 & 33.0 & 28.0 \\
\hline Methylene blue consumption & {$[\mathrm{mmol} / 100 \mathrm{~g}]$} & JBAS 10791 & 104.0 & - \\
\hline Chemical composition & & JIS M 8853 & & \\
\hline $\mathrm{SiO}_{2}$ & [\%] & & 59.65 & 62.53 \\
\hline $\mathrm{Al}_{2} \mathrm{O}_{3}$ & [\%] & & 18.29 & 20.52 \\
\hline $\mathrm{Fe}_{2} \mathrm{O}_{3}$ & [\%] & & 7.15 & 4.55 \\
\hline $\mathrm{TiO}_{2}$ & {$[\%]$} & & 0.41 & 0.16 \\
\hline $\mathrm{CaO}$ & {$[\%]$} & & 2.02 & 1.20 \\
\hline $\mathrm{MgO}$ & [\%] & & 3.14 & 2.43 \\
\hline $\mathrm{K}_{2} \mathrm{O}$ & {$[\%]$} & & 0.46 & 0.52 \\
\hline $\mathrm{Na}_{2} \mathrm{O}$ & [\%] & & 2.60 & 2.38 \\
\hline $\mathrm{P}_{2} \mathrm{O}_{5}$ & [\%] & & 0.13 & 0.05 \\
\hline $\mathrm{MnO}$ & [\%] & & 0.01 & 0.00 \\
\hline Ignition loss & {$[\%]$} & & 6.15 & 5.66 \\
\hline
\end{tabular}

turer), and the initial thickness was $6.0-7.0 \mathrm{~mm}$. Table 1 summarizes the basic properties.

\section{Prehydration Test}

Prehydration tests were conducted (1) to prepare the prehydrated GCLs before the hydraulic conductivity test and (2) to evaluate the effects of the prehydration condition on the water content distribution. Figure 1 shows the apparatus for the prehydration test. In order to focus on the prehydration process generated at an actual site, this test simulated a process where an installed GCL was hydrated by absorbing moisture from base layer soil.

The following procedure was used. According to JIS A 1210, Toyoura sand or decomposed granite soil was compacted at a water content $(15 \%$ or $20 \%)$ using a compaction test mold, which measured $10 \mathrm{~cm}$ in diameter, $12.7 \mathrm{~cm}$ in height, and $1,000 \mathrm{~cm}^{3}$ in volume. Table 2 and Fig. 2 show the basic properties of Toyoura sand and decomposed granite soil. The water retention curves were evaluated according to JGS 0151-2000, “Test Method for Water Retentivity of Soils". The compacted soil was removed to an acrylic mold, which had a $10 \mathrm{~cm}$ diameter and $15 \mathrm{~cm}$ height, and was used as the base layer of the prehydration test. Next, the GCL was trimmed to a $10 \mathrm{~cm}$ diameter and then it was placed on the base layer with a confining pressure of $5 \mathrm{kPa}$. The acrylic mold with the base layer was placed in a water tank, which was $60 \mathrm{~cm}$ in width $\times 30 \mathrm{~cm}$ in depth $\times 35 \mathrm{~cm}$ in height, with or without a water level of $1 \mathrm{~cm}$ as water supply source, and the tank was closed. Following this, the tank was placed in a constant temperature room controlled at $20^{\circ} \mathrm{C}$. The prehydrated GCL was prepared by removing from the acrylic mold after the GCL was hydrated for a curing period of $\geq 7$ days. Total number of the GCLs subjected to various conditions of prehydration was 49 as listed in Table 3.

After the prehydration test, 25 specimens of the pre-

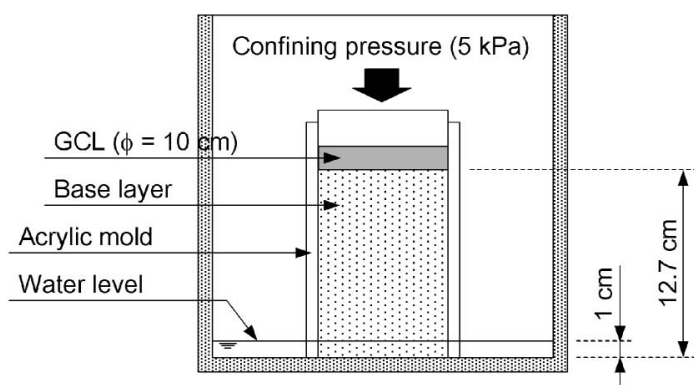

Fig. 1. Apparatus for prehydration test

hydrated GCLs were used for the hydraulic conductivity test as shown in the following subsection, while others were used to investigate the water content distribution. The water content distribution was evaluated by measuring the water content values of 16 species of a prehydrated GCL, which is divided as shown in Fig. 3. From their water content values, the average, $w_{\text {ave }}$, and the standard deviation, $w_{\text {std }}$, the coefficient of variation, $\delta_{\text {cov }}$, were evaluated as follows:

$$
\begin{aligned}
& w_{\text {ave }}=\frac{1}{n} \sum_{\imath=1}^{n} w_{\mathrm{i}} \\
& w_{\text {std }}=\sqrt{\frac{1}{n} \sum_{\imath=1}^{n}\left(w_{\mathrm{i}}-w_{\mathrm{ave}}\right)^{2}} \\
& \delta_{\mathrm{cov}}=\frac{w_{\text {std }}}{w_{\text {ave }}}
\end{aligned}
$$

where $n$ is the number of the sampling species $(n=16$ in this study). The average water content distribution, $w_{\text {ave }}$, indicates the prehydration water content, and the coefficient of variation in the water content distribution, $\delta_{\text {cov }}$, indicates the heterogeneity of the distribution. 
Table 2. Properties of base layer soils used

\begin{tabular}{|c|c|c|c|c|}
\hline Property & Unit & Standard & Toyoura sand & $\begin{array}{l}\text { Decomposed } \\
\text { granite soil }\end{array}$ \\
\hline Soil particle density & {$\left[\mathrm{g} / \mathrm{cm}^{3}\right]$} & JIS A 1202 & 2.630 & 2.677 \\
\hline Natural water content & {$[\%]$} & JIS A 1203 & 0.05 & 0.45 \\
\hline Optimum water content & [\%] & JIS A 1210 & 17.00 & 10.90 \\
\hline Hydraulic conductivity & {$[\mathrm{cm} / \mathrm{s}]$} & JIS A 1218 & $1.42 \times 10^{-2}$ & $3.73 \times 10^{-5}$ \\
\hline Soil pH & {$[-]$} & JGS 0211 & 8.04 & 7.93 \\
\hline Electric conductivity & {$[\mathrm{S} / \mathrm{m}]$} & JGS 0212 & 0.02 & 0.02 \\
\hline Soil particle size distribution & & JIS A 1204 & & \\
\hline $2000>\mu \mathrm{m}$ & [\%] & & 0.00 & 15.64 \\
\hline $2000-75 \mu \mathrm{m}$ & [\%] & & 100.00 & 69.06 \\
\hline $75-5 \mu \mathrm{m}$ & [\%] & & 0.00 & 12.69 \\
\hline$<5 \mu \mathrm{m}$ & [\%] & & 0.00 & 2.62 \\
\hline Chemical composition & & JIS M 8853 & & \\
\hline $\mathrm{SiO}_{2}$ & [\%] & & 94.04 & - \\
\hline $\mathrm{Al}_{2} \mathrm{O}_{3}$ & [\%] & & 2.78 & - \\
\hline $\mathrm{Fe}_{2} \mathrm{O}_{3}$ & {$[\%]$} & & 0.58 & - \\
\hline $\mathrm{TiO}_{2}$ & [\%] & & 0.24 & - \\
\hline $\mathrm{CaO}$ & [\%] & & 0.16 & - \\
\hline $\mathrm{MgO}$ & [\%] & & 0.11 & - \\
\hline $\mathrm{K}_{2} \mathrm{O}$ & [\%] & & 1.42 & - \\
\hline $\mathrm{Na}_{2} \mathrm{O}$ & {$[\%]$} & & 0.32 & - \\
\hline $\mathrm{P}_{2} \mathrm{O}_{5}$ & {$[\%]$} & & 0.01 & - \\
\hline $\mathrm{MnO}$ & {$[\%]$} & & 0.01 & - \\
\hline Ignition loss & {$[\%]$} & & 0.33 & 1.00 \\
\hline
\end{tabular}

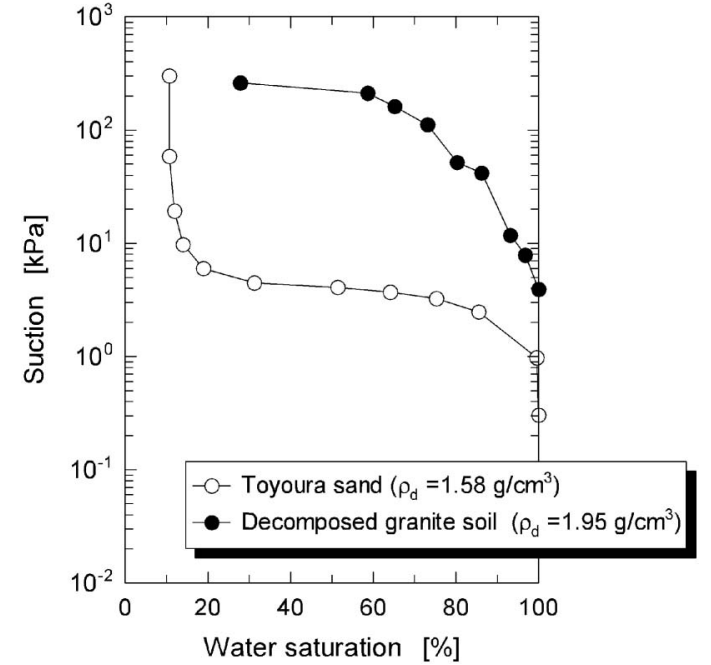

Fig. 2 Water retention curves of base layer soils

\section{Hydraulic Conductivity Test}

Twenty-five specimens of the GCLs prepared in the above prehydration tests were used for the hydraulic conductivity test in order to discuss the prehydration effect on the barrier performance of GCLs against the permeation of chemical solutions. Calcium chloride solutions with a molar concentration of $0.1-0.5 \mathrm{M}$ were used as the permeant liquids to clarify the prehydration effects on the hydraulic conductivity of GCLs: this concentration level has an influence to deteriorate nonprehydrated GCLs (Katsumi et al., 2007). The hydraulic conductivity test was conducted according to ASTM D 5084, "Standard Test Methods for Measurement Hydraulic Conductivity of Saturated Porous Materials Using a Flexible Wall Permeameter'. Figure 4 shows the apparatus. The hydraulic conductivity test was performed using a flexible-wall permeameter with a cell pressure between $20-30 \mathrm{kPa}$ and an average hydraulic gradient of 90 in a constant temperature room controlled at $20^{\circ} \mathrm{C}$.

To prepare the specimen, the prehydrated GCL was cut into a diameter of $6 \mathrm{~cm}$. Here the average and variance of the water content of the GCLs were indirectly estimated from the water content values of the remaining bentonite pieces after this trimming. The prepared specimen was sandwiched between two filter papers attached with the woven geotextiles, and placed in the apparatus. The sides of the specimen were restrained with a rubber membrane, which received a hydraulic pressure of $20-30 \mathrm{kPa}$ by filling an outside cell with water so that the solution could permeate through the specimen without leaking out of the specimen. The hydraulic conductivity tests were continuously performed, and lasted at least a year to investigate the long-term change in the hydraulic conductivity.

\section{RESULTS AND DISCUSSION}

\section{Water Content Distribution after Prehydration}

The prehydration tests focused on evaluating the following effects: (1) the type of soil material used as the base layer, (2) the initial water content of the soil, (3) the water supply from the water table like groundwater, (4) the type of bentonite contained in the GCL, (5) the contact face, woven side or nonwoven side of the GCL, on the base layer, and (6) the curing period during prehydration. Although the base layer is compacted under the same condition according to JIS A 1210 in all the prehydration tests, the physical heterogeneity in the base layer also affects the prehydration effects. But, this study does not evaluate the effects of the heterogeneity in the 
Table 3. Results of prehydration tests

\begin{tabular}{|c|c|c|c|c|c|c|c|c|c|}
\hline \multicolumn{6}{|c|}{ Prehydration condition } & \multirow{3}{*}{\multicolumn{3}{|c|}{$\frac{\text { Result }}{\frac{\text { End of testing }}{\text { Prehydration water content }^{1}}}$}} & \multirow{4}{*}{$\begin{array}{c}\text { Note } \\
\begin{array}{c}\text { Continues to } \\
\text { hydraulic } \\
\text { conducitivty test? }\end{array}\end{array}$} \\
\hline \multirow{3}{*}{ Test No. } & \multicolumn{2}{|c|}{ Base layer type } & \multicolumn{3}{|c|}{ GCL type and curing conditions } & & & & \\
\hline & \multirow{2}{*}{$\begin{array}{l}\text { Soil type and } \\
\text { its water content }\end{array}$} & \multirow{2}{*}{$\begin{array}{l}\text { Supply from } \\
\text { water table? }\end{array}$} & \multirow{2}{*}{$\begin{array}{l}\text { Bentonite } \\
\text { form }\end{array}$} & \multirow{2}{*}{$\begin{array}{c}\text { Contact } \\
\text { face with } \\
\text { base layer }\end{array}$} & \multirow{2}{*}{$\begin{array}{l}\text { Curing } \\
\text { period } \\
\text { [day] }\end{array}$} & & & & \\
\hline & & & & & & $w_{\text {ave }}[\%]$ & $w_{\text {std }}[\%]$ & $\delta_{\text {cov }}[-]$ & \\
\hline$\# 01$ & Toyoura sand $(15 \%)$ & No & Powdered & $\mathrm{W}$ & 7 & 89.7 & 10.7 & 0.12 & \\
\hline$\# 02$ & & No & Powdered & NW & 7 & 110.8 & 4.8 & 0.04 & \\
\hline$\# 03$ & & Yes & Granular & W & 7 & 82.2 & 33.0 & 0.40 & \\
\hline$\# 04$ & & Yes & Granular & W & 7 & 82.9 & 31.3 & 0.38 & Yes \\
\hline$\# 05$ & & Yes & Granular & W & 7 & 106.5 & 21.2 & 0.20 & Yes \\
\hline \#06 & & Yes & Granular & W & 31 & 136.2 & 18.8 & 0.14 & Yes \\
\hline$\# 07$ & & Yes & Granular & W & 31 & 141.3 & 18.7 & 0.13 & \\
\hline$\# 08$ & & Yes & Granular & W & 31 & 147.8 & 19.3 & 0.13 & Yes \\
\hline$\# 09$ & & Yes & Granular & NW & 7 & 43.5 & 11.5 & 0.26 & \\
\hline$\# 10$ & & Yes & Granular & NW & 7 & 83.2 & 30.6 & 0.37 & Yes \\
\hline$\# 11$ & & Yes & Granular & NW & 31 & 80.1 & 10.4 & 0.13 & Yes \\
\hline$\# 12$ & & Yes & Granular & NW & 31 & 119.5 & 29.1 & 0.24 & Yes \\
\hline$\# 13$ & & Yes & Powdered & $\mathrm{W}$ & 7 & 109.7 & 11.0 & 0.10 & Yes \\
\hline \#14 & & Yes & Powdered & W & 7 & 134.1 & 11.9 & 0.09 & \\
\hline$\# 15$ & & Yes & Powdered & W & 7 & 144.6 & 17.3 & 0.12 & \\
\hline$\# 16$ & & Yes & Powdered & W & 31 & 177.1 & 9.4 & 0.05 & Yes \\
\hline$\# 17$ & & Yes & Powdered & W & 31 & 192.1 & 22.6 & 0.12 & Yes \\
\hline$\# 18$ & & Yes & Powdered & NW & 7 & 134.1 & 9.0 & 0.07 & \\
\hline$\# 19$ & & Yes & Powdered & NW & 7 & 155.8 & 15.8 & 0.10 & Yes \\
\hline$\# 20$ & & Yes & Powdered & NW & 7 & 162.9 & 11.4 & 0.07 & Yes \\
\hline$\# 21$ & & Yes & Powdered & NW & 31 & 188.8 & 19.9 & 0.11 & Yes \\
\hline$\# 22$ & Toyoura sand $(20 \%)$ & No & Powdered & $\mathrm{W}$ & 7 & 100.1 & 10.5 & 0.10 & \\
\hline$\# 23$ & & No & Powdered & NW & 7 & 89.5 & 11.0 & 0.12 & \\
\hline$\# 24$ & & Yes & Powdered & W & 7 & 118.4 & 8.5 & 0.07 & \\
\hline$\# 25$ & & Yes & Powdered & NW & 7 & 120.7 & 9.7 & 0.08 & \\
\hline$\# 26$ & Decomp. granite soil (15\%) & No & Granular & $\mathrm{W}$ & 7 & 48.7 & 6.3 & 0.13 & \\
\hline$\# 27$ & & No & Powdered & $\mathrm{W}$ & 7 & 52.3 & 5.3 & 0.10 & Yes \\
\hline$\# 28$ & & No & Powdered & $\mathrm{W}$ & 7 & 80.5 & 7.2 & 0.09 & \\
\hline$\# 29$ & & No & Powdered & $\mathrm{W}$ & 31 & 89.6 & 1.6 & 0.02 & \\
\hline$\# 30$ & & Yes & Granular & W & 7 & 78.7 & 14.4 & 0.18 & \\
\hline$\# 31$ & & Yes & Granular & W & 31 & 145.2 & 5.8 & 0.04 & \\
\hline \#32 & & Yes & Powdered & W & 7 & 126.5 & 6.2 & 0.05 & Yes \\
\hline$\# 33$ & & Yes & Powdered & $\mathrm{W}$ & 7 & 138.5 & 13.9 & 0.10 & Yes \\
\hline$\# 34$ & & Yes & Powdered & W & 31 & 177.1 & 7.4 & 0.04 & \\
\hline$\# 35$ & & Yes & Powdered & $\mathrm{W}$ & 31 & 189.7 & 18.3 & 0.10 & \\
\hline$\# 36$ & & Yes & Powdered & W & 31 & 200.6 & 13.9 & 0.07 & Yes \\
\hline$\# 37$ & & Yes & Powdered & W & 93 & 177.5 & 8.8 & 0.05 & \\
\hline$\# 38$ & Decomp. granite soil $(20 \%)$ & No & Granular & W & 7 & 76.1 & 11.7 & 0.15 & \\
\hline$\# 39$ & & No & Powdered & W & 7 & 98.8 & 3.7 & 0.04 & Yes \\
\hline \#40 & & No & Powdered & W & 31 & 110.2 & 0.5 & 0.00 & \\
\hline \#41 & & Yes & Granular & $\mathrm{W}$ & 7 & 103.4 & 18.4 & 0.18 & \\
\hline$\# 42$ & & Yes & Granular & $\mathrm{W}$ & 31 & 144.9 & 5.4 & 0.04 & \\
\hline$\# 43$ & & Yes & Granular & W & 31 & 160.4 & 4.3 & 0.03 & \\
\hline$\# 44$ & & Yes & Powdered & $\mathrm{W}$ & 7 & 120.5 & 4.4 & 0.04 & Yes \\
\hline$\# 45$ & & Yes & Powdered & W & 7 & 138.4 & 8.8 & 0.06 & Yes \\
\hline$\# 46$ & & Yes & Powdered & W & 7 & 146.4 & 17.1 & 0.12 & \\
\hline \#47 & & Yes & Powdered & W & 31 & 175.4 & 2.5 & 0.01 & \\
\hline \#48 & & Yes & Powdered & W & 31 & 266.1 & 43.8 & 0.16 & Yes \\
\hline$\# 49$ & & Yes & Powdered & W & 93 & 192.6 & 6.9 & 0.04 & \\
\hline
\end{tabular}

${ }^{1}$ The values of the GCLs used for the hydraulic conductivity tests are evaluated from the water contents of bentonite pieces left when GCL is trimmed to $6 \mathrm{~cm}$ in the diameter for the test.

base layer. Table 3 summarizes the results of the prehydration tests. Heterogeneity of bentonite mass per area in GCL might also affect the prehydration effect. In this study, however, the effect of this heterogeneity on the prehydration was not investigated, because the GCL cannot be accurately divided into small species to measure the distribution of mass per unit area.
Figures 5(a) and (b) show the water content distribution of the GCL after prehydration when Toyoura sand and decomposed granite soil with an initial water content of $15 \%$ were used as the base layer, respectively. The water content distribution of each soil is almost the same.

Figures 5(b) and (c) show the effects of the water supply from the water table like groundwater on the water con- 


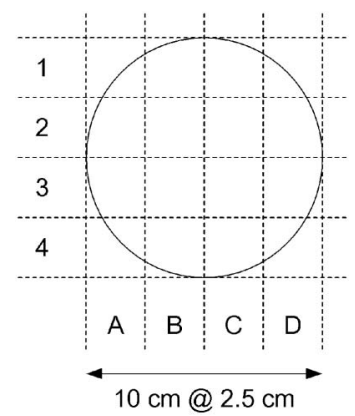

Fig. 3. Division of prehydrated GCL

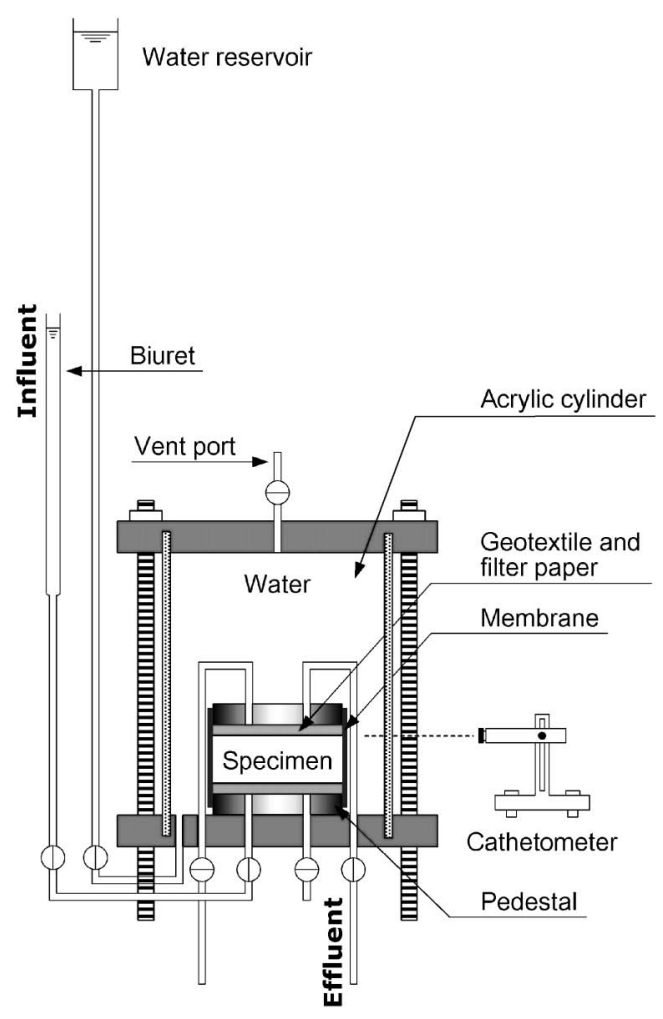

Fig. 4. Apparatus for hydraulic conductivity test

tent distribution after prehydration. A difference in the prehydration water content, which is the average water content distribution, is observed. The base layer with the water table increased the prehydration water content to $144.6 \%$. However, the base layer without the water table also increased although the increased prehydration water content reached only $89.7 \%$. Hence, in actual sites, the presence of a groundwater table and the depth from the ground surface to the groundwater table are important factors, which affect the prehydration effect.

Figures 5(c) and (d) show the water content distribution of GCLs that contains powdered bentonite and granular bentonite, respectively. The bentonite form significantly affects the average and the coefficient of variation of the prehydration water content distribution. The powdered bentonite increases the prehydration water content more than granular bentonite. In addition, pow- dered bentonite homogenizes the water content distribution after prehydration more than granular bentonite. It is probably because, even when one bentonite granular gets wet, it may not be easy for the pore water in the granular to freely disperse to another neighboring granular beyond the space between these granules. Therefore, using a GCL containing powdered bentonite effectively improves both the prehydration water content and the heterogeneity of its distribution in a short curing period.

However, a long-term curing period improves the prehydration water content and the heterogeneity of its distribution, even if a GCL containing granular bentonite is used. Figures 5(e) and (f) show the water content distribution when the curing period is 31 days; in contrast, Figs. 5(c) and (d) show the water content distribution when the curing period is 7 days. Increasing the curing period from 7 to 31 days homogenize the water content distribution of both GCLs. In particular, a significant change appears in the water content distribution of the GCL with granular bentonite. The prehydration water content increased from $82.9 \%$ to $141.3 \%$, while the coefficient of variation decreased from 0.38 to 0.13 . Figures 6 and 7 show the effects of the curing period on the prehydration water content and the heterogeneity of its distribution, respectively. These figures include all the experiment results shown in Table 3. Increasing of the curing period improves the prehydration water content and the heterogeneity of its distribution in all the prehydration conditions tested. However, a curing period greater than certain days did not cause a significant change in either the prehydration water content or heterogeneity. The curing period is dependent on the soil properties of the base layer, the GCL properties, and the actual depth from the ground surface where the GCL is installed to the water table; In this experiment, a curing period longer than 31 days did not cause a significant change in either the prehydration water content or heterogeneity.

Hence, it is concluded that prolonging the curing period and employing GCLs with the powder bentonite are effective measures for enhancing the prehydration water content and for homogenizing the water content distribution. However, as for the contact face (nonwoven side or woven side) of GCLs with the base layer, there was no clear effect on the water content distribution after prehydration.

\section{Hydraulic Conductivity of Prehydrated GCLs}

The purpose of the hydraulic conductivity tests was to evaluate the hydraulic conductivity of the prehydrated GCLs against aggressive chemical solutions, and to discuss the prehydration effect by comparing the prehydrated GCLs to nonprehydrated GCLs in the hydraulic conductivity. Table 4 summarizes the results of the hydraulic conductivity tests. This table shows the relations between the water content distribution of the GCLs and their hydraulic conductivity values. The water content distribution of the GCLs, which were used in the hydraulic conductivity test, was indirectly estimated from the water 


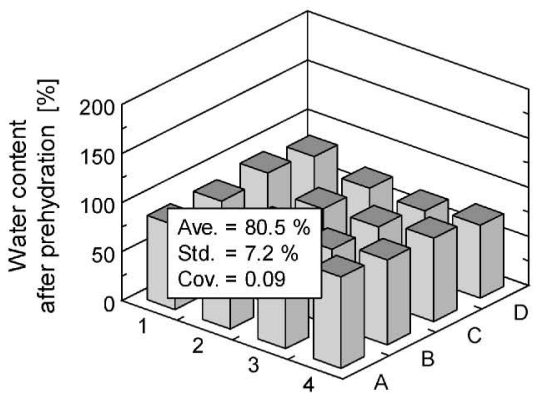

(a) Powd.B on DGS without WL after 7 days

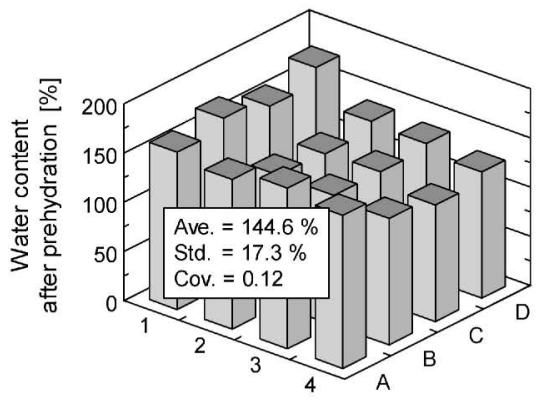

(c) Powd.B on TS with WL after 7 days

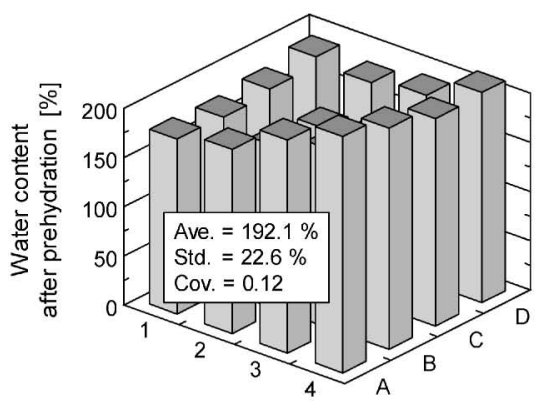

(e) Powd.B on TS with WL after 31 days

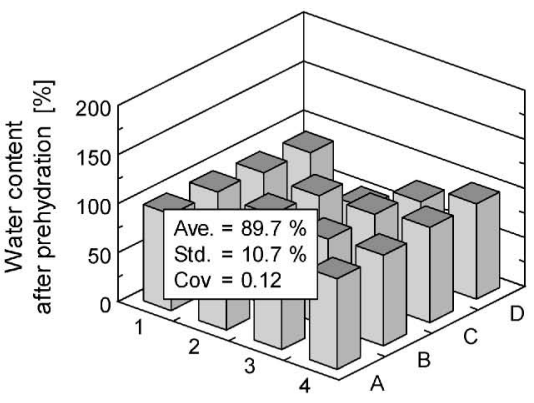

(b) Powd.B on TS without WL after 7 days

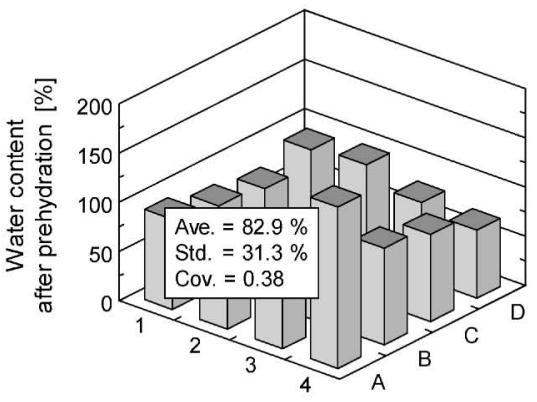

(d) Gran.B on TS with WL after 7 days

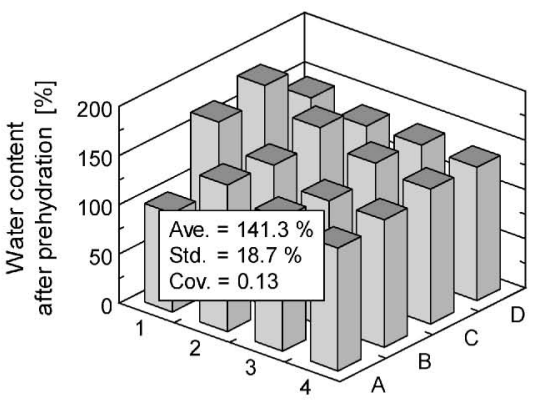

(f) Gran.B on TS with WL after 31 days

Fig. 5. Distribution of prehydration water content of GCLs; where Powd.B = powdered bentonite GCL, Gran.B=granular bentonite GCL, DGS $=$ decomposed granite soil, $T S=$ Toyoura sand, and $W L=$ water level

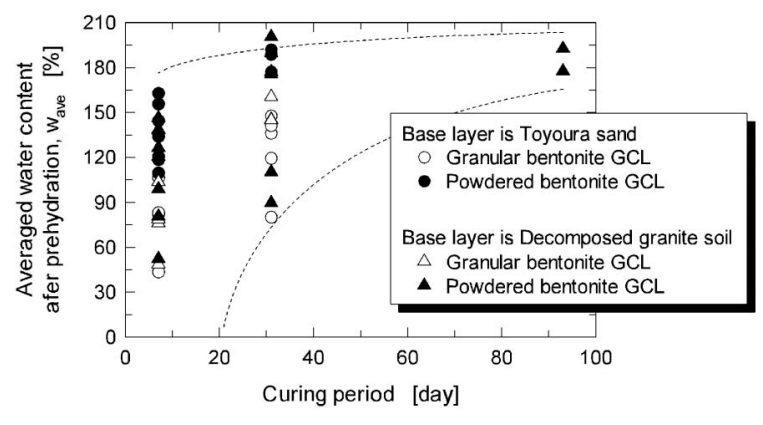

Fig. 6. Effect of curing period on prehydration water content

content values of the bentonite pieces that remained when the prehydrated GCLs were trimmed from a diameter of $10 \mathrm{~cm}$ to $6 \mathrm{~cm}$. Trimming was necessary in order for the samples to work in the hydraulic conductivity test. The hydraulic conductivity value was determined by conducting a long-term test, which lasted at least a year, and the

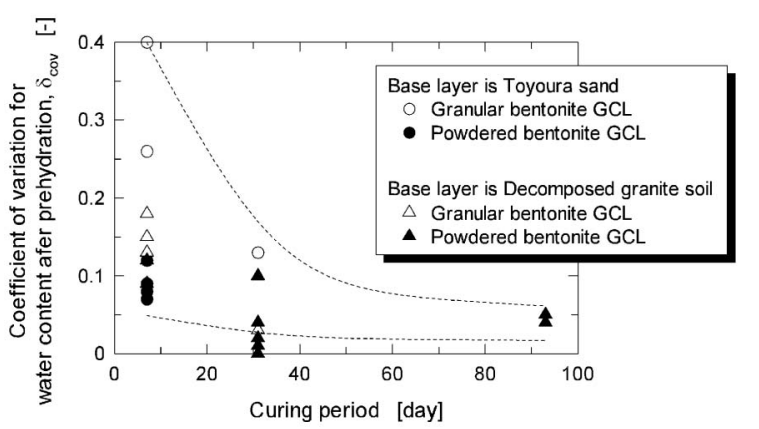

Fig. 7. Effect of curing period on heterogeneity of prehydration water content distribution

chemical equilibrium state was checked before the test was terminated.

Figure 8 shows examples of data obtained in the longterm hydraulic conductivity tests. The thickness of GCLs was observed by the cathetometer once a day, and then 
Table 4. Results of hydraulic conductivity tests using $\mathbf{C a C l}_{2}$ solutions

\begin{tabular}{|c|c|c|c|c|c|c|c|c|c|c|c|c|c|}
\hline \multirow{3}{*}{ Test No. } & \multicolumn{3}{|c|}{$\begin{array}{l}\text { Permeant solution } \\
\left(\mathrm{CaCl}_{2} \text { solution }\right)\end{array}$} & \multicolumn{5}{|c|}{ Testing material (GCL) } & \multicolumn{5}{|c|}{ End of testing (Hydraulic conductivity test) } \\
\hline & \multirow{2}{*}{$\begin{array}{l}\text { Molar conc. } \\
{[\mathrm{M}]}\end{array}$} & \multirow{2}{*}{$\begin{array}{c}\mathrm{pH} \\
{[-]}\end{array}$} & \multirow{2}{*}{$\begin{array}{c}\mathrm{EC} \\
{[\mathrm{S} / \mathrm{m}]}\end{array}$} & \multirow{2}{*}{ Bentonite form } & \multirow{2}{*}{ Prehydration } & \multicolumn{3}{|c|}{ Prehydration water content } & \multirow{2}{*}{$\begin{array}{l}\text { Time } \\
\text { [year] }\end{array}$} & \multirow{2}{*}{$\begin{array}{l}\mathrm{PVF} \\
{[-]}\end{array}$} & \multirow{2}{*}{$\begin{array}{l}\mathrm{pH} \\
{[-]}\end{array}$} & \multirow{2}{*}{$\begin{array}{c}\mathrm{EC} \\
{[\mathrm{S} / \mathrm{m}]}\end{array}$} & \multirow{2}{*}{$\begin{array}{c}k \\
{[\mathrm{~cm} / \mathrm{s}]}\end{array}$} \\
\hline & & & & & & $w_{\text {ave }}[\%]$ & $w_{\text {std }}[\%]$ & $d_{\mathrm{cov}}[-]$ & & & & & \\
\hline - & 0.10 & 8.56 & 16.85 & Powdered & NP & - & - & - & $<1$ & 12.22 & 8.19 & 17.81 & $1.83 \times 10^{-8}$ \\
\hline$\# 27$ & & & & Powdered & $\mathrm{P}$ & 52.3 & 5.3 & 0.10 & $<2$ & 53.09 & 7.06 & 18.00 & $6.16 \times 10^{-9}$ \\
\hline$\# 44$ & & & & Powdered & $\mathrm{P}$ & 120.5 & 4.4 & 0.04 & $<2$ & 43.44 & 7.31 & 16.60 & $1.19 \times 10^{-9}$ \\
\hline$\# 36$ & & & & Powdered & $\mathrm{P}$ & 200.6 & 13.9 & 0.07 & $<1$ & 78.65 & 6.53 & 16.98 & $2.06 \times 10^{-8}$ \\
\hline- & 0.25 & 8.88 & 36.70 & Granular & NP & - & - & - & $<1$ & 9.45 & - & - & $3.37 \times 10^{-5}$ \\
\hline$\# 11$ & & & & Granular & $\mathrm{P}$ & 80.1 & 10.4 & 0.13 & $<2$ & 30.81 & - & - & $3.41 \times 10^{-9}$ \\
\hline$\# 04$ & & & & Granular & $\mathrm{P}$ & 82.9 & 31.3 & 0.38 & $<2$ & 82.69 & - & - & $1.78 \times 10^{-8}$ \\
\hline$\# 10$ & & & & Granular & $\mathrm{P}$ & 83.2 & 30.6 & 0.37 & $<2$ & 18.92 & 6.69 & 38.80 & $1.48 \times 10^{-6}$ \\
\hline$\# 05$ & & & & Granular & $\mathrm{P}$ & 106.5 & 21.2 & 0.20 & $<2$ & 25.01 & - & - & $2.91 \times 10^{-9}$ \\
\hline$\# 12$ & & & & Granular & $\mathrm{P}$ & 119.5 & 29.1 & 0.24 & $<2$ & 57.30 & - & - & $1.12 \times 10^{-8}$ \\
\hline$\# 06$ & & & & Granular & $\mathrm{P}$ & 136.2 & 18.8 & 0.14 & $<2$ & 14.31 & - & - & $1.13 \times 10^{-8}$ \\
\hline- & & & & Powdered & NP & - & - & - & $<1$ & 10.60 & - & - & $9.29 \times 10^{-6}$ \\
\hline$\# 39$ & & & & Powdered & $\mathrm{P}$ & 98.8 & 3.7 & 0.04 & $<2$ & 93.69 & 6.89 & 39.60 & $1.21 \times 10^{-8}$ \\
\hline$\# 13$ & & & & Powdered & $\mathrm{P}$ & 109.7 & 11.0 & 0.10 & $<2$ & 43.96 & - & - & $1.45 \times 10^{-8}$ \\
\hline$\# 32$ & & & & Powdered & $\mathrm{P}$ & 126.5 & 6.2 & 0.05 & $<2$ & 39.85 & 6.80 & 38.70 & $6.63 \times 10^{-9}$ \\
\hline$\# 19$ & & & & Powdered & $\mathrm{P}$ & 155.8 & 15.8 & 0.10 & $<2$ & 123.88 & - & - & $3.20 \times 10^{-8}$ \\
\hline$\# 20$ & & & & Powdered & $\mathrm{P}$ & 162.9 & 11.4 & 0.07 & $<2$ & 92.74 & 6.68 & 39.70 & $2.07 \times 10^{-8}$ \\
\hline$\# 16$ & & & & Powdered & $\mathrm{P}$ & 177.1 & 9.4 & 0.05 & $<2$ & 91.25 & 6.55 & 40.90 & $3.92 \times 10^{-9}$ \\
\hline$\# 21$ & & & & Powdered & $\mathrm{P}$ & 188.8 & 19.9 & 0.11 & $<2$ & 79.18 & 6.56 & 38.00 & $5.55 \times 10^{-9}$ \\
\hline$\# 17$ & & & & Powdered & $\mathrm{P}$ & 192.1 & 22.6 & 0.12 & $<2$ & 24.80 & - & - & $7.74 \times 10^{-9}$ \\
\hline- & 0.50 & 9.24 & 62.40 & Powdered & NP & - & - & - & $<1$ & 23.72 & 6.57 & 66.00 & $2.80 \times 10^{-5}$ \\
\hline$\# 45$ & & & & Powdered & $\mathrm{P}$ & 138.4 & 8.8 & 0.06 & $<1$ & 32.41 & 6.78 & 76.50 & $2.92 \times 10^{-8}$ \\
\hline \#33 & & & & Powdered & $\mathrm{P}$ & 138.5 & 13.9 & 0.10 & $<1$ & 19.26 & 6.81 & 65.70 & $4.64 \times 10^{-8}$ \\
\hline$\# 48$ & & & & Powdered & $\mathrm{P}$ & 266.1 & 43.8 & 0.16 & $<1$ & 19.69 & 6.72 & 73.50 & $4.11 \times 10^{-8}$ \\
\hline
\end{tabular}

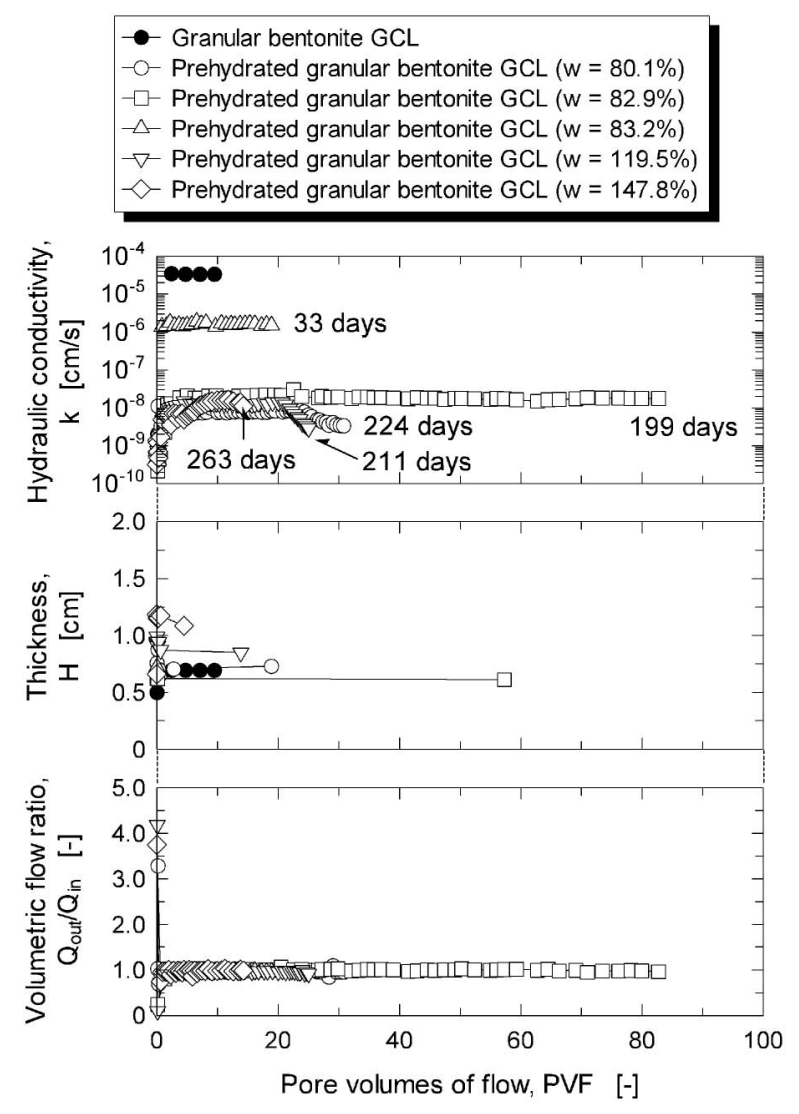

Fig. 8. Changes in the hydraulic conductivity, the thickness, and the volumetric flow rate of GCLs containing granular bentonite with time the hydraulic conductivity was evaluated using the latest thickness. The hydraulic conductivity of prehydrated GCLs to $\mathrm{CaCl}_{2}$ solutions was first as low as that of GCL to water, but gradually increased with time. When the concentration of the permeant liquids was low, the hydraulic conductivity of the prehydrated GCLs settled down in $k \approx 1.0 \times 10^{-8} \mathrm{~cm} / \mathrm{s}$. The effluent liquid was used to measure its $\mathrm{pH}$ and electric conductivity. In order to reach the chemical equilibrium state before the test is terminated, the electric conductivity ratio of the influent and effluent should fall within 0.9-1.1 according to ASTM D 6766 "'Standard Test Method for Evaluation of Hydraulic Properties of Geosynthetic Clay Liners Permeated with Potentially Incompatible Liquids".

Figure 9 shows the effects of the prehydration water content on the hydraulic conductivity of prehydrated GCLs against $0.1-0.5 \mathrm{M} \mathrm{CaCl}_{2}$ solutions. When the water content was $>50 \%$, the prehydration water content barely influenced the hydraulic conductivity of the prehydrated GCL. The hydraulic conductivity of the prehydrated GCLs was approximately $1.0 \times 10^{-8} \mathrm{~cm} / \mathrm{s}$ even when the molar concentration of the permeant $\mathrm{CaCl}_{2}$ solution was more than $0.25 \mathrm{M}$, which significantly affects the decrease in the hydraulic conductivity of nonprehydrated GCLs. All the prehydrated GCLs with powdered bentonite indicated the low hydraulic conductivity of $\approx 1.0 \times 10^{-8}$ $\mathrm{cm} / \mathrm{s}$. In contrast, one of prehydrated GCLs with granular bentonite indicated the high hydraulic conductivity of $1.5 \times 10^{-6} \mathrm{~cm} / \mathrm{s}$, although the others indicated the low hydraulic conductivity. Thus, it might be concluded that 


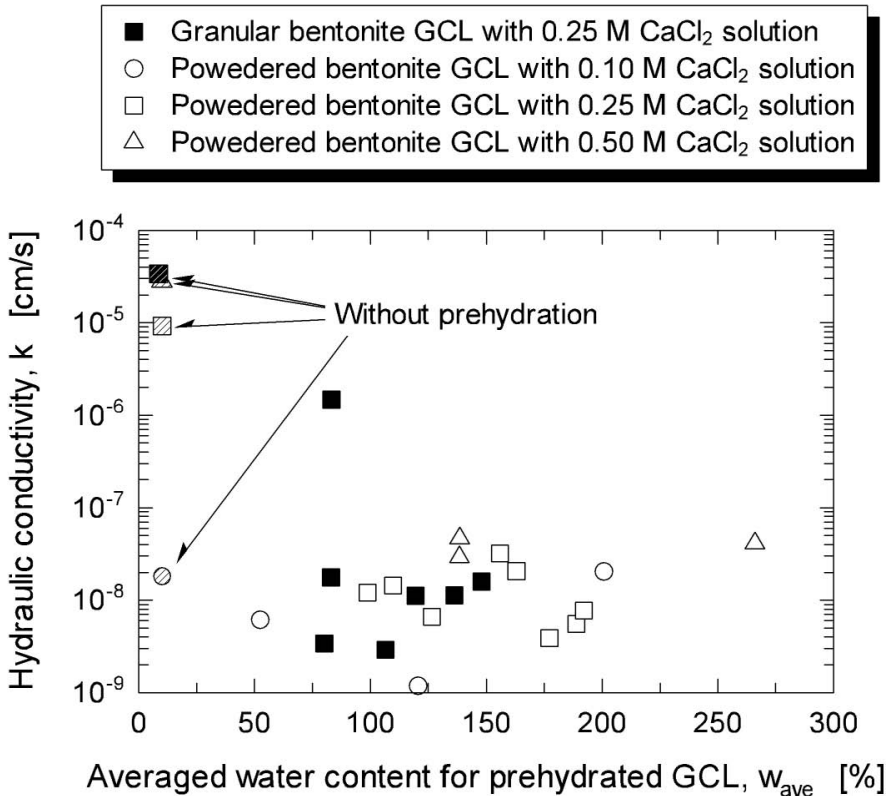

Fig. 9. Effects of the prehydration water content on the hydraulic conductivity of GCLs

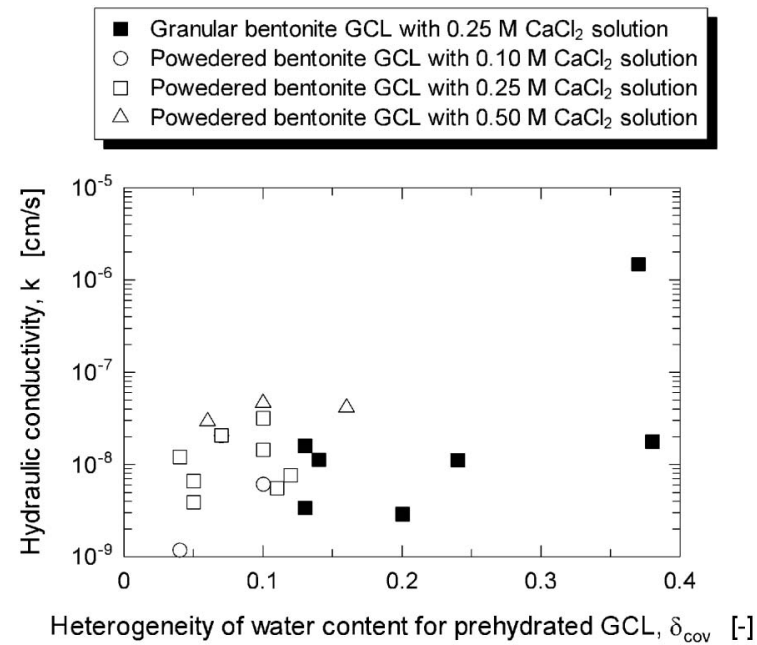

Fig. 10. Effects of the heterogeneity of the water content distribution on the hydraulic conductivity of GCLs

GCLs with granular bentonite do not necessarily obtain the low hydraulic conductivity by the prehydration. It may be because the water content distribution of the prehydrated GCLs with granular bentonite became easily heterogeneous as shown in Fig. 5. Even if the sufficiently swelled parts included in the heterogeneously prehydrated GCL can exhibit the low hydraulic conductivity, the insufficiently swelled parts exhibit the high hydraulic conductivity so that the hydraulic conductivity of the entire GCL with the heterogeneous water content distribution becomes high.

Figure 10 shows the effects of the heterogeneity of the water content distribution on the hydraulic conductivity of prehydrated GCLs. In this study, it was not clearly recognized that the hydraulic conductivity of prehydrated GCLs was increased with the heterogeneity (the coefficient of variation) of the water content distribution. It may be because the way to evaluate the heterogeneity of the water content distribution of GCLs used for the hydraulic conductivity tests was not applicable. The water content distribution was indirectly estimated from the water contents of bentonite pieces left when GCL is trimmed to $6 \mathrm{~cm}$ in the diameter for the hydraulic conductivity test. The water content distribution estimated by this way may not be the exact water content distribution of the GCL used for the hydraulic conductivity test. Although the effects of the heterogeneity of the water content distribution on the hydraulic conductivity cannot be clearly shown by this evaluation, GCLs with granular bentonite would be prehydrated more heterogeneously than those with powdered bentonite. One of the prehydrated GCLs with granular bentonite would indicate the higher hydraulic conductivity than the others due to uncertainty of their prehydration. The homogeneity of the water content distribution of the prehydrated GCL has been considered an important factor for improving the chemical resistance.

Figure 11 shows the hydraulic conductivity values of nonprehydrated and prehydrated GCLs. The prehydration treatment maintains an extremely low hydraulic conductivity even to the permeation of the aggressive chemical solutions such as $\mathrm{CaCl}_{2}$ solutions. In particular, the effect of the prehydration treatment greatly appears in the hydraulic conductivity when the $\mathrm{CaCl}_{2}$ solution with a high concentration permeates into the GCL. The nonprehydrated GCL is deteriorated by the permeation of a $\mathrm{CaCl}_{2}$ solution with a molar concentration of $0.5 \mathrm{M}$ so that the hydraulic conductivity increases up to $k=2.8 \times$ $10^{-5} \mathrm{~cm} / \mathrm{s}$, while the prehydrated GCLs against the $0.5 \mathrm{M}$ $\mathrm{CaCl}_{2}$ solution showed $k \approx 1.0 \times 10^{-8} \mathrm{~cm} / \mathrm{s}$. The three orders of magnitude difference appears in the hydraulic conductivity between the nonprehydrated GCL and the 


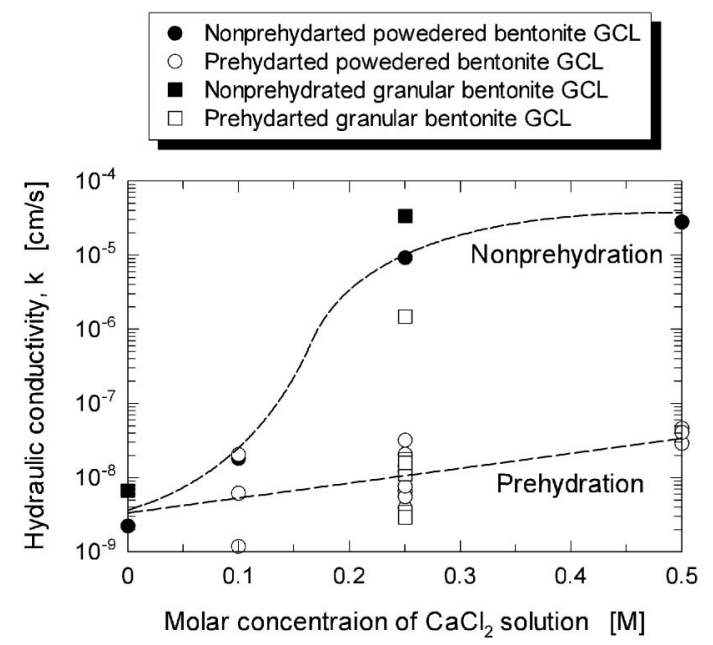

Fig. 11. Comparison between non-prehydrated GCLs and prehydrated GCLs in the hydraulic conductivity

prehydrated GCL. It is concluded that prehydration effectively improves the chemical resistance of GCLs.

\section{CONCLUSIONS}

When GCLs are applied as bottom liners at waste containment facilities, the GCLs are naturally prehydrated by absorbing moisture from unsaturated base layers. In consideration of the prehydration process at actual sites, this study investigated the effects of the water content distribution of prehydrated GCLs on their barrier performance against $\mathrm{CaCl}_{2}$ solutions, which were used to simulate waste leachates. From the prehydration test and the hydraulic conductivity test, the following conclusions were obtained.

(1) Prehydrated GCLs with powdered bentonite have the higher water content as the average and more homogeneous water content distribution than those with granular bentonite. Hence, GCLs with powdered bentonite can be highly and homogenously prehydrated. Furthermore, employing GCLs with powdered bentonite is an effective method for improving barrier performance against chemical attack.

(2) The curing period for prehydration influences the water content and the homogeneity of prehydrated GCLs. In this experimental condition, when the curing period is prolonged from 7 to 31 days, the water content increases and its coefficient of variation, which is a parameter that indicates the heterogeneity of the water content distribution, decreases. However, the change in the water content and its coefficient of variation is negligible when the curing period was prolonged from 31 to 93 days.

(3) Although GCLs with granular bentonite are lowly and heterogeneously prehydrated, prolonging the curing period improves their water content distribution.

(4) Most of the prehydrated GCLs exhibit a low hydraulic conductivity of $k \approx 1.0 \times 10^{-8} \mathrm{~cm} / \mathrm{s}$ against $\mathrm{CaCl}_{2}$ solutions with concentrations between 0.1 and 0.5
M. This hydraulic conductivity value is about 1,000 times lower at the maximum than that of the nonprehydrated GCLs.

(5) However, prehydrated GCLs have been considered not to exhibit such a low hydraulic conductivity when the water content distribution of the prehydrated GCLs was strongly heterogeneous. Heterogeneous prehydration permits the parts, which are insufficiently swelled with a low water content, to pass the permeant solutions. The hydraulic conductivity values of such heterogeneously prehydrated GCLs will widely vary. It was easy for GCLs with granular bentonite to be heterogeneously prehydrated.

To maintain the required barrier performance for GCLs installed as large-scale bottom liners at waste containment facilities, it is important to consider the effects of geological and hydrological conditions such as not only retention characteristics, groundwater level but also physical heterogeneity of base layer soils (the physical heterogeneity effects are not investigated in this paper) when designing the GCL and the curing period.

\section{ACKNOWLEDGMENTS}

Helpful comments and discussions were provided by Professor Masashi Kamon (Kyoto University). The GCLs were provided by Marubeni Tetsugen Co., Ltd. Assistance with the experimental work was provided by former students of Ritsumeikan University, including Shugo Numata, Masato Yokoi, and Kazuyoshi Hanamoto.

\section{REFERENCES}

1) Barroso, M., Touze-Foltz, N., Maubeuge, K. and Pierson, P. (2006): Laboratory investigation of flow rate through composite liners consisting of a geomembrane, a GCL and a soil liner, Geotextiles and Geomembranes, 24, 139-155.

2) Bonaparte, R., Othman, M. A., Rad, N. R., Swan, R. H. and Vander Linde, D. L. (1996): Evaluation of various aspect of GCL performance, Report of 1995 Workshop on Geosynthetic Clay Liners, EPA/600/R-96/149.

3) Daniel, D. E., Shan, H.-Y. and Anderson, J. D. (1993): Effects of partial wetting on the performance of bentonite component of a geosynthetic clay liner, Geosynthetics '93, 3, 1482-1496.

4) Daniel, D. E., Trautwein, S. J. and Goswami, P. K. (1997): Measurement of hydraulic properties of geosynthetic clay liners using a flow box, Testing and Acceptance Criteria for Geosynthetic Clay Liners, ASTM STP 1308 (ed. by L. W. Well), 196-207.

5) Dickinson, S. and Brachman, R. W. I. (2006): Deformations of a geosynthetic clay liner beneath a geomembrane wrinkle and coarse gravel, Geotextiles and Geomembranes, 24(5), 285-298.

6) Gates, W. P. (2004): Crystalline swelling of organo-modified clays in ethanol-water solutions, Applied Clay Science, 27, 1-12.

7) Gates, W. P., Nefiodovas, A. and Peter, P. (2004): Permeability of an organo-modified bentonite to ethanol-water solutions, Clays and Clay Minerals, 52(2), 192-203.

8) Giroud, J.-P., Thiel, R. S., Kavazanjian, E. and Lauro, F. J. (2002): Hydrated area of a bentonite layer encapsulated between two geomembranes, Proceedings 7th International Conference on Geosynthetics (eds. by Ph. Delmas, J. P. Gourc, and H. Girard), 2, $827-832$.

9) Jo, H. Y., Katsumi, T., Benson, C. H. and Edil, T. B. (2001): 
Hydraulic conductivity and swelling of non-prehydrated GCLs permeated with single species salt solutions, Journal of Geotechnical and Geoenvironmental Engineering, 127(7), 557-567.

10) Katsumi, T. and Fukagawa, R. (2005): Factors affecting chemical compatibility and barrier performance of GCLs, Proc. 16 ICSMGE, 2285-2288.

11) Katsumi, T., Ishimori, H., Fukagawa, R. and Hanamoto, K. (2006): Long-term hydraulic conductivity of modified GCL permeated with inorganic chemical solutions, Proc. 8th International Conference on Geosynthetics, 1, 167-170.

12) Katsumi, T., Ishimori, H., Ogawa, A., Yoshikawa, K., Hanamoto, K. and Fukagawa, R. (2007): Hydraulic conductivity of nonprehydrated geosynthetic clay liners permeated with inorganic solutions and waste leachates, Soils and Foundations, 47(1), 79-96.

13) Katsumi, T., Ishimori, H., Onikata, M. and Fukagawa, R. (2008): Long-term barrier performance of modified bentonite materials against sodium and calcium permeant solutions, Geotextiles and Geomembranes, 26, 14-30.

14) Kolstad, D. C., Benson, C. H. and Edil, T. B. (2004a): Hydraulic conductivity and swell of nonprehydrated geosynthetic clay liners permeated with multispecies inorganic solutions, Journal of Geotechnical and Geoenvironmental Engineering, 130(12), 12361249.

15) Kolstad, D. C., Benson, C. H., Edil, T. B. and Jo, H. Y. (2004b): Hydraulic conductivity of a dense prehydrated GCL permeated with aggressive inorganic solutions, Geosynthetics International, 11(3), 233-241

16) LaGatta, M. D., Boardman, B. T., Cooley, B. H. and Daniel, D. E. (1997): Geosynthetic clay liners subjected to differential settlement, Journal of Geotechnical and Geoenvironmental Engineering, 123(5), 402-410.

17) Laird, D. A. (206): Influence of layer charge on swelling of smectites, Applied Clay Science, 34, 74-87.

18) Lake, C. B. and Rowe, R. K. (2000): Diffusion of sodium and chloride through geosynthetic clay liners, Geotextiles and Geomembranes, 18, 103-131.

19) Lake, C. B. and Rowe, R. K. (2004): Volatile organic compound diffusion and sorption coefficients for a needle-punched GCL, Geosynthetics International, 11(4), 257-272.

20) Lee, J. M. and Shackelford, C. D. (2005): Concentration dependency of the prehydration effect for a geosynthetic clay liner, Soils and Foundations, 45(4), 27-41.

21) Lo, I. M.-C., Liljestrand, H. M. and Daniel, E. D. (1994): Hydraulic conductivity and adsorption parameters for pollutant transport through montmorillonite and modified montmorillonite clay liner materials, Hydraulic Conductivity and Waste Contaminant Transport in Soils, ASTM STP 1142, 422-438.

22) Lo, I. M.-C., Mak, R. K.-M. and Lee, S. C.-H. (1997): Modified clays for waste containment and pollutant attenuation, Journal of Environmental Engineering, 123(1), 25-32.

23) Lo, I. M.-C. and Yang, X. (2001): Use of organoclay as secondary containment for gasoline storage tanks, Journal of Environmental Engineering, 127(2), 154-161.

24) Norrish, K. (1954): The swelling of montmorillonites, Discussions of Faraday Society, 18, 120-134.

25) Norrish, K. and Quirk, J. P. (1954): Crystalline swelling of montmorillonite, use of electrolytes to control swelling, Nature, 173, 255-257.

26) Onikata, M., Kondo, M. and Kamon, M. (1996): Development and characterization of multiswellable bentonite, Environmental Geotechnics, 587-590.
27) Onikata, M., Kondo, M., Hayashi, N. and Yamanaka, S. (1999a): Complex formation of cation-exchanged montmorillonites with propylene carbonate: Osmotic swelling in aqueous electrolyte solutions, Clays and Clay Minerals, 47(5), 672-677.

28) Onikata, M., Kondo, M. and Yamanaka, S. (1999b): Swelling of formamide-montmorillonite complexes in polar liquids, Clay and Clay Minerals, 47(5), 678-681.

29) Petrov, R. J. and Rowe, R. W. (1997): Geosynthetic clay liner (GCL)-chemical compatibility by hydraulic conductivity testing and factors impacting its performance, Canadian Geotechnical Journal, 34, 863-885.

30) Posner, A. M. and Quirk, J. P. (1964): Changes in basal spacing of montmorillonite in electrolyte solutions, Journal of Colloid and Interface Science, 19, 798-812.

31) Rowe, R. K. (1998): Geosynthetics and the minimization of contaminant migration through barrier systems beneath solid waste, Proc. 6th International Conference on Geosynthetics, 1, 27-103.

32) Rowe, R. K. (2005): Long-term performance of contaminant barrier systems, Géotechnique, 55(9), 631-678.

33) Rowe, R. K. and Orsini, C. (2003): Effect of GCL and subgrade type on internal erosion in GCLs under high gradients, Geotextiles and Geomembranes, 21, 1-24.

34) Rowe, R. K., Quigley, R. M., Brachman, R. W. I. and Booker, J. R. (2004): Barrier Systems for Waste Eisposal Facilities, Taylor \& Francis Books Ltd., London.

35) Ruhl, J. L. and Daniel, D. E. (1997): Geosynthetic clay liners permeated with chemical solutions and leachates, Journal of Geotechnical and Geoenvironmental Engineering, 123(4), 369-381.

36) Shackelford, C. D. (1994): Waste-soil interactions that alter hydraulic conductivity, Hydraulic Conductivity and Waste Contaminant Transport in Soils, ASTM STP 1142, 111-168.

37) Shackelford, C. D., Benson, C. H., Katsumi, T., Edil, T. B. and Lin, L. (2000): Evaluating the hydraulic conductivity of GCLs permeated with non-standard liquids, Geotextiles and Geomembranes, 18, 133-161.

38) Shan, H.-Y. and Lai, Y.-J. (2002): Effect of hydrating liquid on the hydraulic properties of geosynthetic clay liners, Geotextiles and Geomembranes, 20, 19-38.

39) Slade, P. G. and Quirk, J. P. (1990): The limited crystalline swelling of smectites in $\mathrm{CaCl} 2, \mathrm{MgCl} 2$ and $\mathrm{LaCl} 3$ solutions, Journal of Colloid and Interface Science, 144(1), 18-26.

40) Slade, P. G., Quirk, J. P. and Norrish, K. (1991): Crystalline swelling of smectite samples in concentrated $\mathrm{NaCl}$ solutions in relation to layer change, Clays and Clay Minerals, 39(3), 234-238.

41) Touze-Foltz, N., Duquennoi, C. and Gaget, E. (2006): Hydraulic and mechanical behavior of GCLs in contact with leachate as part of a composite liner, Geotextiles and Geomembranes, 24, 188-197.

42) Trauger, R. and Darlington, J. (2000): Next-generation geosynthetic clay liners for improved durability and performance, Proc. 14th GRI Conference, 255-267.

43) Vasko, S. M., Jo, H. Y., Benson, C. H., Edil, T. B. and Katsumi, T. (2001): Hydraulic conductivity of partially prehydrated geosynthetic clay liners permeated with aqueous calcium chloride solutions, Geosynthetics Conference 2001, 685-699.

44) Viswanadham, B. V. S., Jessberger, H. L. and Rao, G. V. (1999): Discussion to 'Geosynthetic clay liners subjected to differential settlement', Journal of Geotechnical and Geoenvironmental Engineering, 125(2), 159-160.

45) Yang, X. and Lo, I. M.-C. (2004): Flow of gasoline through composite liners, Journal of Environmental Engineering, 130(8), 886-890. 